\title{
Struktur teks Geguritan Candrabherawa dalam tradisi tulis bahasa Bali
}

\section{Wayan Agus Gunada}

Sekolah Tinggi Agama Hindu Negeri Gde Pudja Mataram

Correspondence : gunadastahngpmataram@gmail.com

\begin{abstract}
Abstrak
Salah satu karya sastra yang masih hidup sebagai bentuk tradisi tulis dalam struktur kebahasaan Bahasa Bali adalah geguritan. Geguritan adalah karya sastra yang dibentuk berdasarkan pupuh dan di lagukan oleh dua orang dimana satu orang yang melagukan dan satu orang yang mengartikan atau memaknai masing-masing pupuh. Geguritan Candrabherawa merupakan geguritan yang dikawi oleh I Ketut Ruma mengacu kepada lontar Purwwagama Sasana. Kajian geguritan Candrabherawa ini berpusat kepada analisis struktur teksnya yang dianggap unik dan memiliki ciri tersendiri terkait rasa estetika dan kemampuan pengarangnya, hasil analisa disimpulkan terdapat komponen yang membentuk struktur teks geguritan ini dan yang menonjol adanya perbedaan padalingsa pupuh pembentuk geguritan Candrabherawa yang terkesan keluar dari pakem yang ada namun perbedaan ini umumnya terjadi karena pengarang ingin mempertahankan alur cerita sehingga pemilihan kata dalam jumlah pada sedikit berbeda dengan struktur pada selanjutnya dalam pupuh-pupuh pembentuk teks geguritan Candrabherawa namun perbedaan tersebut tidak mengubah kesan estetika dari geguritan tersebut.
\end{abstract}

Kata kunci: sastra, struktur, geguritan, Candrabherawa

\section{Pendahuluan}

Bali merupakan salah satu pulau dimana mayoritas masyarakatnya menganut ajaran Agama Hindu. (Wijaya, 2014) menyebutkan dalam sejarahnya agama Hindu ternyata sebelum penaklukan oleh Majapahit tahun 1343, Agama Hindu di Bali tidak disebut sebagai agama Hindu, nama-nama atau aliran yang pernah muncul begitu banyak kemudian setelah dikuasai oleh Majapahit, semua aliran agama berada di bawah hegemoni agama siwa Siddhanta (Wijaya, 2014:148). Hal ini menandakan bahwa perkembangan Hindu tidak serta merta terjadi tetapi melalui proses yang panjang, salah satunya dalam proses penyerangan Majapahit ke Bali. 
Penyerangan Majapahit ini tentu bukan hanya sekedar penyerangan dalam bentuk peperangan namun lebih jauh setelah pendudukan Majapahit di Bali maka tata budaya antara kebudayaan Jawa dengan Bali terjadi semacam akulturasi dibanyak segi kehidupan masyarakat Bali. Salah satunya dalam bidang karya sastra yaitu Geguritan. Mengapa geguritan kemudian dapat dikategorikan sebuah karya sastra yang mendapat pengaruh jawa karena banyak sekali pupuh yang membentuk struktur geguritan sebagai sebuah karya sastra diciptakan oleh orang-orang Jawa. (Dhanu Priyo Prabowo, V. Risti Ratnawati, Suyami, Mumfangati, 2002) menyebutkan bahwa didalam khazanah perpuisian jawa juga ditemukan jenis puisi yang disebut dengan geguritan. Pada awalnya geguritan adalah puisi jawa yang selalu didahului dengan kalimat "sun gegurit" atau "sun anggurit" yang berarti aku mengarang atau membaca geguritan (2002:11). Jadi dapat disimpulkan bahwa geguritan merupakan sastra jawa yang berarti aku mengarang dan ketika bertemu dengan budaya Bali maka pakem-pakem serta unsur budaya Bali ikut berkembang dalam proses perkembangan geguritan, umumnya di Bali.

(Dyah Nur Lailyana, 2017) menjelaskan bahwa karya sastra merupakan sebuah hasil kreativitas seorang yang memiliki unsur keindahan. Lebih lanjut disebutkan bahwa dalam penciptaan karya sastra terdapat pengalamanpengalaman hidup dari pengarang sastra tersebut (2017:1). Secara Filosofis (Budiasa, 2019) menyebutkan bahwa masyarakat Hindu di Bali sangat mengenal dengan karya-karya sastra lama terutama geguritan, geguritan biasanya disalurkan lewat shanti Dharma Gita, melalui gita seseorang dapat memperdalam isi agama dan nilai keagamaan, dengan gita dapat memperhalus perasaan dan menyehatkan pernafasan (Budiasa, 2019:304). Dharmagita dalam Modul yang disusun oleh Sugimawa, dkk (2009) menyebutkan bahwa dharma gita merupakan istilah yang berasal dari bahasa Sanskerta yaitu dharma dan gita, yang secara arti kata maka dapat diartikan sebagai nyanyian dharma atau nyanyian kebaikan, namun umumnya dharma gita selalu diidentikkan dengan istilah agama Hindu sehingga secara mendalam maka makna dharma gita ialah suatu lagu atau nyanyian yang dipergunakan dalam pelaksanaan upacara agama Hindu (2009:2).

Secara Teoritis Agastia dalam (Bagus, Nandana, Istri, Mulyawati, \& Putu, 2017) menyebutkan bahwa geguritan merupakan suatu karya sasta tradisional, geguritan mempunyai sistem konvensi sastra tertentu yang ketat, dimana geguritan dibentuk oleh pupuh (2017:304). Jadi dapat disimpulkan bahwa geguritan merupakan sebuah karya sastra, dimana bentuk karya sastra dari geguritan diatur oleh aturan-aturan tradisional. Secara struktur geguritan dibentuk oleh pupuh-pupuh.

Secara Empiris Dibia dalam Anak Agung Istri Dwi Wulandari, I Wayan Mandra (2018) geguritan adalah salah satu jenis sastra Bali tradisional yang masih hidup dan berkembang dalam masyarakat Bali. Lebih lanjut menyatakan 
belakangan ini, warga masyarakat Bali Di desa maupun di Kota, menjadi semakin bergairah terhadap aktivitas budaya lama yaitu pesantian (dari kata santi yang berarti damai) dan pada dasarnya pesantian adalah pembacaan karya-karya sastra klasik bertembang yang ditulis dalam metrum sekar agung dan sekar madya (2018:1-2). Lebih dalam kemudian Geguritan merupakan salah satu jenis sastra Bali Tradisional yang masih hidup dan berkembang di dalam masyarakat Bali (Sura, Loka, Sudarsana, \& Artayasa, 2019:75).

Geguritan sebagai sebuah karya sastra, bukan hanya sekedar karya sastra namun lebih dalam terdapat esensi ajaran tattwa dan susila yang sangat dalam. Nilai-nilai ajaran agama Hindu juga sangat kental menghiasi teks-teks dalam karya geguritan, karena esensi geguritan adalah santi, damai, sehingga ajaran dharma sebagai inti ajaran agama menjadi fokus utama dalam geguritan sebagai salah satu pelaksanaan proses beragama. Salah satu geguritan yang didalamnya cukup menyimpan berbagai ajaran agama Hindu adalah geguritan Candrabherawa. Geguritan Candrabherawa merupakan salah satu geguritan yang dikarang dan disusun oleh I Ketut Ruma yang mengisahkan peperangan antara kerajaan Hastinapura dengan kerajaan Dewantara karena adanya semacam perbedaan dalam melaksanakan ajaran agama.

Secara pragmatis, penelitian terhadap geguritan Candrabherawa merupakan penelitian lanjutan terkait penelitian sebelumnya, (Gunada, 2020) menyebutkan bahwa dalam geguritan Candrabherawa tersimpan berbagai ajaran suci Hindu yang dapat dijadikan sebagai suatu nilai dan pedoman dalam internalisasi pendidikan karakter (2020:118). Selain karena dalamnya ajaran agama Hindu yang tersimpan didalamnya, secara struktural kebahasaan ternyata memiliki keunikan dari segi bahasa dan lebih jauh merupakan geguritan yang disusun berdasarkan Lontar sehingga tentu didalamnya menyimpan berbagai ajaran agama Hindu. Namun dalam penelitian ini hanya terfokus pada struktur teks terkait dengan kebahasaan sastra sehingga walaupun hanya terpokus pada struktur kebahasaan namun dari struktur inilah kemudian diharapkan ajaranajaran suci Hindu sebagai jiwa dalam geguritan dapat dibedah dalam kajian lain nantinya terkait geguritan Candrabherawa.

\section{Metode}

Geguritan Candrabherawa dalam pengkajian untuk mencari struktur teksnya berdasarkan analisis kebahasaan menggunakan metodologi penelitian ilmiah. Pendekatan yang digunakan menggunakan pendekatan kualitatif deskriftif yang bermakna penelitian dilakukan dengan menggunakan asas-asas penelitian kualitatif yang menjelaskan segala fenomena dengan kata-kata narasi untuk menjelaskan segala deskripsi dan gambaran data yang terdapat didalam geguritan Candrabherawa sesuai dengan fokus penelitian yang dilakukan yakni membedah struktur teksnya. Objek penelitian dalam penelitian ini adalah teks geguritan Candrabherawa yang disusun oleh I Ketut Ruma. Dalam mengkaji dan 
membedah segala data terkait dengan rumusan masalah yang dibahas menggunakan jenis data kualitatif dengan dua sumber data yaitu data primer dan data sekunder. Data primer didapatkan melalui pengkajian teks geguritan Candrabherawa dan data sekunder didapatkan melalui studi pustaka yang relevan dalam penelitian ini. Instrumen penelitian dalam penelitian teks ini menggunakan dua instrumen yaitu peneliti sebagai pengumpul data dan instrumen kunci untuk menginterpretasikan data terkait teks geguritan Candrabherawa dan instrumen pelengkap yang menunjang proses penelitian. Untuk mengumpulkan data menggunakan teknik studi pustaka dengan mengkaji teks geguritan Candrabherawa dan mengkaji pustaka yang relevan dan menunjang penelitian ini. Untuk menganalisis serta memeriksa keabsahan data ini maka digunakan teknik analisis data Miles Huberman yaitu reduksi data, penyajian dan verifikasi data serta mengolaborasikan dengan teknik trianggulasi data untuk mendapatkan data yang sah dan valid.

\section{Hasil dan pembahasan}

Berdasarkan hasil kajian terhadap geguritan candrabherawa ini maka ditemukan sejumlah elemen atau komponen yang membentuk struktur teks geguritan ini, antara lain sebagai berikut.

\section{Penggunaan gaya bahasa dalam Geguritan Candrabherawa}

Gaya bahasa dalam geguritan tutur Candrabherawa secara keseluruhan menggunakan dua jenis gaya bahasa, yaitu gaya bahasa penegasan dan gaya bahasa perbandingan. Gaya bahasa ini terdapat dalam beberapa kutipan sebagai berikut :

"Dhuh Dèwa Sang Bhimasèna, lawutang tuturang jani, indik tatujon Idèwa, di hajěng para papatih, bahudañdha para mantri, mangda sami padha wruh, Aryya Brahmä Wisnuwiśwara, Mahādèwa Sangkarā di, Rudra Sambhu, Mahèsora mwah nè lyanan" (Geguritan Candrabherawa, Pupuh Sinom, pada : 32)

Terjemahan bebasnya : wahai kamu sang Bhimasena, lanjutkan ceritamu sekarang, terkait tujuan kamu, di depan para patih, pendeta para menteri, agar semua tahu, arya Brahma Wisnuwiswara mahadewa sangkara, rudra shambu, mahesora dan yang lain.

Dari kutipan teks diatas maka dapat disimpulkan bahwa gaya bahasa penegasan dibuktikan dengan kalimat " mangda sami padha wruh", agar tujuan dari sang Bhimasena diketahui oleh para hadirin di kerajaan Raja Candra Bhairawa

"Sang Bhima gělis manimbal, syaku kahutus nè jani, dutta Srī Dharmmatanaya, mwah Srì Krěsna bhūpati, hinudèśa manglawadi, yan hana wwang salah unduk, siněnggah agamyāgama, ngawè sanghara ning bhumi, 
ngawè lětuh, sasab mraṇa tan pěgatan" (Geguritan Candrabherawa, Pupuh Sinom, pada :33)

Terjemahan bebasnya : Sang bhimapun lekas membalas, aku diutus sekarang, utusan Sri Dharmmatanaya, dan Sri Raja Kresna, berjalan ke segala tempat, kalau ada yang salah dalam berperilaku, menentang ajaran agama, membuat sengsara di Bhumi, membuat kekotoran, wabah penyakit tak hentihenti.

Dari kutipan teks diatas gaya bahasa penegasan ditegaskan melalui teks "yan hana wwang salah unduk, siněnggah agamyāgama, ngawè sanghara ning bhumi, ngawè lětuh, sasab mraņa tan pěgatan" ini memberikan penegasan bahwa kedatangan Bhima sebagai utusan dari Hastinapura adalah untuk menegakkan ajaran Dharma (Agama) karena adanya kekeliruan dalam pelaksanaan agama di Kerajaan Dewantara sehingga terjadi sengsara di bumi dan membuat wabah penyakit yang tiada henti-hentinya.

Gaya bahasa perbandingan dapat dimaknai sebagai suatu gaya bahasa yang menegaskan dua hal yang berbeda dan disandingkan untuk mendapatkan kesan yang berbeda antara satu hal dengan hal lain. Dalam teks geguritan tutur Candrabherawa maka gaya bahasa perbandingan dapat dilihat dari kutipan teks berikut :

"To awanan tan sangkaning saja tatas, ring daging kārmma sanyaşin, bantas bisa ñěmbah, tan tatas mulaning sembah, tungtung sěmbah tan kuningin, miwah sang aněmbah, talěr tan kahuningin (geguritan Candrabherawa, pupuh durma, pada : 6)"

Terjemahan bebasnya : itulah mengapa agar semua paham, dengan isinya karma sanyasa, sebatas bisa menyembah, tidak paham awalnya menyembah, ikut-ikutan menyembah namun tidak tahu, dengan yang menyembah, tidak pula diketahui

"Twara ada suměkěn ngělah panawang, dèwa di sanggar malinggih, mèru kabuyutan, sunya suhung sujatinña, twara tahèn jerit-jerit, nagihang bantěn, tong ada Dèwa ñakitin (geguritan Candrabherawa, pupuh durma, pada : 8)"

Terjemahan bebasnya : tidak ada yang benar-benar punya pengetahuan, dewa di sanggah ber-stahana, alam semesta kosong yang sejati, tidak pernah berteriak, meminta banten, tidak ada dewa yang menyakiti.

"Yadyastun ada anak mangěntungang, sinah twara ñakitin, manahè ngawinang, ngawè panampènè bhina, ngawè takut ngawè bani, manah wwang müdha, papak papak karyyanin. (geguritan Candrabherawa, pupuh durma, pada : 10)"

Terjemahan bebasnya : walaupun ada orang yang membuang, tidak pernah menyakiti, pikiran yang membuat, membuat pikiran terbagi, membuat takut membuat berani, pikiran dengan perbuatan, semua-semua dikerjakan. 
Dari beberapa petikan teks diatas maka gaya bahasa perbandingan yang digunakan adalah untuk membandingkan antara pelaksanaan prosesi keagamaan atau pelaksanaan yajna di Hastinapura dengan Dewantara. Dimana Hastinapura lebih menekankan kepada yajna dalam bentuk upacara, sedangkan Dewantara tidak demikian. Dewantara lebih menekankan kepada esensi dari pelaksanaan yajna, bukan kepada kulit luarnya. Itu ditegaskan dalam petikan teks yang terjemahan bebasnya lihat arca tersebut walaupun tidak dibuatkan banten dan bahkan di buang tidak akan menyakiti, pikiran yang membuat segalanya.

\section{Tema dalam Geguritan Candrabherawa}

Menurut Sukada (1987) dalam Gde bagus Made Surya Pradnyana, dkk, (2018) menjelaskan bahwa tema tidak lain daripada ide pokok, ide sentral atau ide yang bertindak sebagai titik tolak pengarang dalam penyusunan sebuah cerita. Dalam geguritan Tutur Candrabherawa ditemukan bahwa tema utama adalah terkait ajaran Catur Marga dengan sub tema adalah adanya perbedaan memandang dan melaksanakan ajaran Panca Yadnya antara Panca Pandawa dengan Prabu Candrabhairawa, dimana Panca Pandawa lebih menekankan pelaksanaan ajaran agama dan yadnya melalui bhakti marga sedangkan Prabu Candrabhairawa menekankan keseimbangan diantara semua catur marga.

\section{Alur dalam Geguritan Candrabherawa}

Alur dalam sebuah karya sastra merupakan bagian penting karena alur dapat diartikan sebagai sebuah timeline yang menghubungkan setiap peristiwa yang digambarkan dalam sebuah karya sastra. (Sri Ulina Beru Ginting, 2017) dalam jurnalnya yang mengutip dari Tjahyono (1988) menyebutkab bahwa alur atau plot merupakan struktur penceritaan dalam prosa fiksi yang didalamnya berisi serangkaian kejadian atau peristiwa yang disusun berdasarkan hukum sebab akibat serta logis (2016:151). Jadi dapat diartikan bahwa alur merupakan serangkaian kejadian yang terjadi karena adanya hukum sebab akibat dimana peristiwa yang diceritakan terjadi karena adanya suatu peristiwa di masa lalu yang melatarbelakangi timbulnya peristiwa di masa depan dalam sebuah karya sastra yang susunannya logis.

Dalam geguritan Candrabherawa berdasarkan hasil analisa maka didapatkan beberapa alur yang membentuk struktur rangkaian peristiwa dalam kisahnya. Alur ini terbagi dalam tiga hal yaitu alur sebab, alur akibat dan alur antiklimaks. Alur sebab dimulai dari diperintahkannya para panca pandawa untuk menyebarkan ajaran agama yang berlaku di Hastinapura agar seluruh pelaksanaan upacara bisa seragam diseluruh daerah kekuasaan Hastinapura, oleh karenanya tibalah Bima disebuah kerajaan yang bernama Kerajaan Dewantara yang dalam pelaksanaan keagamaannya tidak selaras dengan prinsip 
Hastinapura sehingga memancing amarah dari Bhima dan tidak tunduknya Raja Candrabhairawa atas titah atau kehendak raja Hastinapura.

Alur akibat dimulai dari pecahnya perang antara kerajaan Hastinapura dengan kerajaan Dewantara dimana masing-masing tokoh saling menunjukkan keberanian dan kepandaian dalam perang tersebut, dalam proses perang itupun tidak ada yang mampu mengalahkan raja Candrabhairawa bahkan Sri Kresna pun kalah sakti oleh beliau sehingga diadakanlah sebuah lomba antara Yudistira dengan Candrabhairawa.

Alur antiklimaks dimulai dari tidakmampunya yuditira untuk menghidupkan kembali sang candrabhairawa hingga meminta pertolongan kepada Dewa Siwa untuk menghidupkan Sang Candrabhairawa. Hingga Sang Raja Dewantara mengaku kalah dan menepati janjinya untuk memberikan anaknya bila kalah perang. Dan terjadi perdamaian diantara dua kerajaan dengan tetap memegang teguh prinsip pelaksanaan acara agama dan penyatuan ajaran karma yoga dengan raja yoga sanyasa sehingga konsep ajaran catur marga bisa seimbang.

\section{Struktur pupuh dalam Geguritan Candrabherawa}

Tutur Candrabherawa sebagai sebuah karya sastra tradisional dalam bentuk geguritan. Terbentuk dari beberapa pupuh. Tjok. Istri Agung Mulyawati R. (2017) dalam penelitiannya menyebutkan Geguritan memiliki ciri-ciri yaitu adanya pupuh-pupuh yang membentuk geguritan tersebut. Geguritan yang dibentuk oleh pupuh tersebut diikat oleh padalingsa, dimana padalingsa sebagai sebuah pola persajakan atau konvensi, merupakan suatu institusi yang mengikat konstruksi suatu geguritan yang dapat dipahami melalui pemahaman masyarakat (sastra) pendukungnya (2017:1). Jadi geguritan dibentuk oleh pupuh-pupuh, dimana pupuh-pupuh ini diatur oleh padalingsa yang merupakan aturan persajakan tradisional dalam karya sastra geguritan di Bali.

\section{Pupuh sinom}

Pupuh Sinom muncul pada awal-awal geguritan sebagai teks pupuh pembuka dimana dalam geguritan Candrabherawa menceritakan awal mula raja dharmawangsa mengutus semua saudaranya keseluruh daerah. Pupuh sinom dalam geguritan Candrabherawa berjumlah 35 pada. Kemunuculan pupuh sinom dalam teks geguritan candrabherawa pada halaman 1-12 pada buku cetaknya. Menurut Agastya dalam Tjok. Istri Agung Mulyawati R (2017) dalam penelitiannya menyebutkan bahwa pupuh sinom diperkirakan karangan sunan Giri yang umumnya digunakan dalam geguritan sebagai penyampaian nasehat, amanat dan beberapa fungsi salah satunya untuk hal-hal yang menggembirakan (2017:31).

Pada pupuh sinom dari hasil analisa terkait padalingsa pada pupuh sinom yang digunakan pada geguritan candrabherawa nampaknya setiap palet pada 
barisan pada-nya memiliki struktur yang berbeda pada beberapa pada seperti pada 1 dan pada 2, ini terlihat pada palet ke III dan VII. Perbedaan padalingsa ini juga terlihat pada beberapa pada yang lain pula. Namun perbedaan pada yang tidak sesuai dengan pakem pupuh padalingsa pada pupuh sinom rasanya tidak terlalu berpengaruh karena tentu ekspresi rasa seniman atau sang kawi dalam penyusunan karya sastra dari penyusun teks geguritan candrabherawa ini juga menjadi pengaruh terdapatnya perbedaan tersebut. Hal ini tentu membuat terjadi semacam pergeseran pakem, namun hal ini mungkin terjadi karena pengarang ingin mempertahankan alur serta plot sesuai dengan cerita sehingga suara pada beberapa palet dalam pada terjadi perbedaan sesuai dengan pakem pupuh sinom pada umumnya

\section{Pupuh durma}

Pupuh Durma dalam teks pupuh kedua geguritan Candrabherawa berjumlah 29 pada. Pupuh ini terdapat pada halaman 12-29 pada buku teks geguritan candrabherawa karangan I Ketut Ruma. (Tjok. Istri Agung Mulyawati R., 2017) dalam penelitiannya menyebutkan bahwa penggunaan pupuh durma umumnya untuk mengisyaratkan hal-hal buruk seperti kekacauan (2017:9). Ini tertulis seperti kutipan dalam pada ke 17 pada teks geguritan Candrabherawa yaitu : "Sakèwala Idèwa dā salah harşa, manira tan pisan bani, maměsěh-měsěhan, těkèn rakan Idèwa, nānghing yan Ida ngrihinin, pacang mayuddhā, manira tan makakirig (pada 17)"

Terjemahan bebasnya : Namun jangan kamu salah paham, aku tidak pernah berani, menyama-nyamai, dengan kakakmu, namun kalau beliau memulai, akan berperang, aku tidak akan minggir.

Kutipan teks diatas dapat diinterpretasikan bahwa akan terjadi semacam kekacauan karena perang, hal ini di mungkinkan terjadi karena ada semacama tantangan jika prabu yudistira memang menginginkan perang karena tindakan raja candrabairawa yang tidak akan menuruti semua kehendak kerajaan Hastinapura, raja candrabairawa tidak ingin berperang namun jika Hastinapura menginginkan maka raja tidak akan takut

Adapun hasil analisa sebagaimana pupuh durma maka dapat disimpulkan sebagai berikut 1) terdapat beberapa perbedaan pada beberapa yaitu pada 1 dan pada 2 yang terlihat pada palet ke II, III, VI dan VII. Hal ini juga terlihat pada beberapa pada pada pupuh Durma dalam teks geguritan candrabherawa. 2) perbedaan padalingsa ini dapat disimpulkan bahwa pengarang ingin mempertahankan alur dari kata-kata yang digunakan dalam palet sebelumnya sehingga lepas dari pakem yang ada sehingga suara antara pada dengan palet pada beberapa padalingsa berbeda bentuknya. 


\section{Pupuh pangkur}

Pupuh pangkur dalam teks pupuh ketiga dalam geguritan Candrabherawa berjumlah 12 pada. Pupuh pangkur ini ditemukan pada halaman 18-21. Mengacu kepada Saputra dalam penelitian Tjok. Istri Agung Mulyawati menyebutkan bahwa pupuh pangkur merupakan karangan Sunan Muria yang umumnya digunakan untuk mengungkapkan perasaan hati yang bersungguh-sungguh (2017:17). Dalam geguritan Candrabherawa maka ini tercermin pada kutipan teks berikut :

"Nānghing yan tan kalinguwang, malih těmpal ring pituduh narapati, kāla irika Iratu, ngalurug Candrabhairawa, mapidabdab gagělaran magagěbug, wadwa miwah para yuddha, pacang ngiringang nrěpati (geguritan Candrabherawa, pupuh pangkur, pada : 9))"

Terjemahan bebasnya : namun kalau tidak dihiraukan, dan ingkar dengan perintah raja, disaat itulah ratu, bertempur dengan Candrabhairawa, mempersiapkan pertarungan, prajurit dan kesatria dalam perang, dan saya akan mengiringi raja"

Dapat diinterpretasikan bahwa kata-kata Si Kresna sebagai penasehat raja Yudistira menyarankan dengan sungguh-sungguh bahwa agar mengutus kembali duta atau utusan untuk menegaskan maksud dari perintah sang prabu, namun jika ingkar serta tidak menurut maka mau tidak mau peranglah yang harus menjadi solusi. Kesungguhan ini terlihat dari kata-kata lanjutan untuk mempersiapkan prajurit aga bersiap-siap dalam perang nantinya.

Berdasarkan data yang sudah dianalisa terhadap pupuh Pangkur maka dapat diberikan beberapa simpulan yaitu terdapat adanya variasi atau perbedaan dalam hal jumlah padalingsa pada beberapa palet. Hal ini terlihat pada I dan II pada palet III dimana jumlah pada pada I palet III berjumlah 8 sedangkan pada II palet III berjumlah 9 sedangkan suara masih sama yaitu suara ' $u$ '. dan perbedaan jumlah palet pada pada-pada yang lain juga terlihat namun suara tidak berubah. Sama seperti simpulan pada pupuh sebelumnya dapat diambil kesimpulan bahwa perbedaan ini karena pengawi tetap ingin mempertahankan alur cerita sehingga setiap pada memang terkait sehingga penggunaan jumlah suara dapat berbeda dan terkesan menyimpang dengan pakem yang ada.

\section{Pupuh ginadha}

Pupuh ginadha dalam teks pupuh keempat dalam geguritan Candrabherawa berjumlah 12 pada. Pupuh ginada ini ditemukan pada halaman 21-24 pada buku teks geguritan Candrabherawa. Menurut I Made Budiasa \& Sukrawati, Cokorda lstri Negari, 1997) menyebutkan bahwa pupuh ginada dipakai untuk melukiskan kesedihan, merana dan kecewa (1997:10). Pengungkapan kekecewaan ini dalam teks geguritan Candrabherawa dengan pupuh ginada terkutip dalam pada sebagai berikut : 
"Ring wawu asapunika, Aryya Brahmä mañawurin, cahi tè Patih Kirata, duwěg cahi mungwang hatur, ring Ida Sang Candranātha, lěngut latig, ban cahi měsuwang pěta (geguritan Candrabherawa, pupuh ginada, pada : 7)"

Terjemahan bebasnya : hanya baru segitu, Arya Brahma membalas, hai kamu patih Kirata, pandai kamu mengeluarkan suara, kepada raja Candrabherawa, kasar sekali bagimu mengeluarkan kata.

"Saja layah tan patulang, tan santul měsuwang muñi, pětanè ñěngsěng timbungan, sok ngulahang siddha pěsu, twara pisan matolihan, měswang muñi, matur ring Ida Sang Natha (geguritan Candrabherawa, pupuh ginada, pada 8)"

Terjemahan bebasnya : benar saja lidah tidak bertulang, tidak berpikir mengeluarkan kata, kata-katamu menyakitkan, mengeluarkan semaunya, tidak sekalipun melihat, mengeluarkan kata, menghadap kepada sang Raja.

Kutipan teks diatas secara jelas menginterpretasikan kekecewaan akibat kemarahan yang dirasakan oleh Arya Brahma akibat dari kata-kata yang dikeluarkan oleh Patih Kirata. Kekecewaan ini muncul karena adanya ancaman yang disampaikan oleh Kerajaan Hastinapura oleh Patih Kirata sebagai duta atau utusan. Ini kemudian mengindikasikan bahwa penggunaan pupuh ginadha dalam geguritan Candrabherawa memang digunakan untuk mengungkapkan alur kekecewaan dari tokoh-tokoh yang dilantunkan dalam lagu pada pupuh yang dikarang.

Data hasil analisa memberikan gambaran secara singkat dari padalingsa yang terdapat pada pupuh ginadha dalam geguritan candrabherawa. Dari hasil analisa dapat disimpulkan bahwa ada semacam beberapa perbedaan padalingsa dalam pada dan palet, salah satunya muncul dalam pada ke 1 dan 2 di palet III. Perbedaan itu muncul pada jumlah guru gatra yang disusun, namun penggunaan suara masih tetap "a" hanya jumlah guru gatra yang berbeda. Perbedaan ini dapat diperkirakan sama seperti yang terjadi pada pupuh-pupuh sebelumnya dikarenakan pengarang tetap ingin mempertahankan alur setiap pada sehingga tidak terkesan adanya loncatan alur yang berbeda, sehingga penggunaan kata dapat terus harmonis setiap pada dan palet. Tentu hal ini akan menyebabkan terjadinya penyimpangan pada pakem-pakem yang ada, namun terlepas dari hal tersebut tidak dapat dipungkiri bahwa ekspresi dari pengarang dalam hal ini penciptaan geguritan Candrabherawa menjadi faktor perbedaan dalam penyusunan geguritan tersebut.

\section{Pupuh durma}

Pupuh durma dalam teks pupuh kelima dalam geguritan Candrabherawa berjumlah 8 pada. Pupuh durma ini kembali muncul dalam geguritan Candrabherawa pada halaman 24-26 pada buku teks geguritan Candrabherawa. Sebagaimana pada penjelasan sebelumnya bahwa penggunaaan pupuh durma ini mengindikasikan untuk mengungkapkan 
perasaan akan terjadinya hal-hal yang buruk. Indikasi ini muncul pada teks berikut :

"Hanè jani těkčdang bawos manira, těkèning gustin cahi, ring Sang Dharmmaputra, muwah Prabhu Kèśawa, manira tan pacang-ajerih, matandingan yuddha, yadyastun musuhè śakti (geguritan Candrabherawa, pupuh durma, Pada : 2)"

Terjemahan bebasnya : yang sekarang sampaikan pesanku, kepada rajamu, kepada Sang Dharmaputra, dan Prabu Kesawa, aku tidak akan takut, bertanding perang, walaupun musuh sakti mandraguna.

"Sabwina manira ñadya mangantosang, mělěd matandingan jurit, ngadu kawišèsan, těkèning Prabhu Krěşna, rèh saking brangti sěngit, těkèn manira, sangkan krodha buka jani (geguritan Candrabherawa, pupuh durma, pada : 3)."

Terjemahan bebasnya : aku akan menunggu, ingin bertanding perang, mengadu kesaktian, dengan Prabu Kresna, karena kemarahan yang meluap, kepadaku, karena disebabkan kemarahanku sekarang.

Kutipan teks geguritan Candrabherawa diatas secara tidak langsung mengungkapkan akan adanya suatu keburukan karena terjadinya perang. Terpicunya perang yang disebabkan perbedaan paham pelaksanaan beragama antara kerajaan Hastinapura dengan kerajaan Dewantara yang berakhir dengan terjadinya perang tentu akan berimplikasi buruk. Sehingga jelas bahwa penggunaan pupuh durma dalam lanjutan alur cerita geguritan Candrabherawa ini untuk menunjukkan dan mengungkapkan suasana yang terkesan akan timbulnya semacam keburukan. Melihat data dari hasil analisa pupuh diatas maka dapat disimpulkan bahwa terdapat beberapa perbedaan yang pertama perbedaan jumlah guru gatra pada beberapa pada contohnya saja pada 1 dan pada 2-8, pada palet I dimana pada 1 berjumlah 11 sedangkan pada 2-8 berjumlah 12. Perbedaan jumlah guru gatra ini juga muncul pada palet-palet lain pada pada-pada selanjutnya. Mengulang kembali penjelasan pada hasil analisa sebelumnya bahwa perbedaan jumlah guru gatra ini diperkirakan untuk tetap menjaga alur cerita dengan pemilihan dan penggunaan kata sehingga tidak terjadi loncatan perbedaan yang besar pada setiap bait teks geguritan dan untuk menjaga harmonisasi alur sehingga tiap palet tetap terlihat harmoni dan selaras.

\section{Pupuh sinom}

Pupuh Sinom dalam teks pupuh keenam dalam geguritan Candrabherawa berjumlah 39 pada. Pupuh sinom kembali muncul pada teks yang ditemukan pada halaman 26-38. Sama seperti yang sidah dijelaskan sebelumna bahwa penggunaan pupuh sinom ini untuk menyampaikan nasehat serta amanat pada teks geguritan. Hal ini muncul pada beberapa teks, ini ditunjukkan pada lagu berikut : 
"ada pitěkět bapa, kapatutan anak istri, manüt grehasta winaya, indikè bhakti ring laki, nè sandang pantěs lakonin, twah lalima katah ipun, rawosè satatā dabdab, hěnto hanè ka ping siki, ping dwan ipun, prajñan ngamělang sakaya (geguritan Candrabherawa, pupuh sinom, pada: 7)"

Terjemahan bebasnya : ada pesan ayah, kewajiban seorang perempuan, merujuk kepada kewajiban perkawinan, yaitu kewajiban kepada suami, yang harus dilakukan, hanya lima jumlahnya, perkataan yang harus dijaga, itu yang pertama, yang kedua, kepintaran melaksanakan kemampuan.

'Nè ping tiga patut sayang, ring biyang aji sang laki, patuh twara mabhinayan, sayangè těkèn swami, ping pat tan maro kasih, těgěp ban swami aukud, ngalantur nè $k a$ ping lima, cèştakāra mangayahin,salwir ipun, swa kāryyaning pakurěnan (geguritan Candrabherawa, pupuh sinom, pada ke 8)" Terjemahan bebasnya : yang ketiga wajib menyayangi, kepada mertua laki dan perempuan, sama tidak boleh berbeda seperti kepada suami, yang keempat tidak boleh mendua (selingkuh), hanya cinta kepada seorang suamu, lanjut yang kelima, mengabdi kepada semua kewajiban perkawinan.

Kutipan teks diatas menceritakan percakapan sang raja Candrabherawa kepada Putrinya yaitu sang Raden Mantri Sang Dyah Ratna Sasangka. Percakapan ayah dan anak ini mengisahkan pemberian amanat dan nasehat sang raja kepada anaknya terkait kewajiban seorang istri ketika sudah menikah. Terdapat lima hal yang wajib dilakukan oleh istri sebagai bentuk dharma seorang perempuan yang sudah kawin. Kata-kata nasehat ini mencerminkan bagaimana kewajiban seorang ayah dalam menjaga dan mendidik anaknya karena berfirasat akan kalah dalam perang. Representasi ini mengindikasikan bahwa pupuh sinom dalam alur cerita selanjutnya digunakan untuk memberikan amanat dan nasehat ini tercermin sebagaimana kutipan teks diatas.

Menganalisa data diatas dapat disimpulkan bahwa terdapat beberapa perbedaan padalingsa dalam beberapa teks pada pupuh sinom yang digunakan. Ini terlihat pada ke 8 dan ke 9 perbedaan ini muncul pada jumlah guru gatra pada palet I, IV dan V digunakan yaitu pada ke 8 berjumlah 8,7 dan 7 sedangkan pada 9 berjumlah 7,8 dan 8 . Selain jumlah guru gatra ditemukan juga perbedaan penggunaan suara pada beberapa pada dan palet salah satunya adalah pada ke 5 palet VII dimana umumnya pada pupuh sinom palet VII menggunakan suara "a" namun pada ke 5 palet VII menggunakan suara "u". perbedaan ini tentu memperlihatkan terjadinya semacam penyimpangan pakem yang ada apalagi perbedaan jumlah guru gatra dan suara yang ada terkesan sekali menyimpang dari pakem. Hanya saja tentu terdapat banyak faktor penyebab, namun dari hasil analisa ini penyebab lebih ditekankan kepada tetap ingin dipertahankannya alur cerita sehingga jumlah kata yang mencitrakan jumlah guru gatra menjadi berbeda pada beberapa palet namun perbedaan ini tidak sama sekali merubah keindahan yang terjadi karena tetap adanya harmonisasi setiap kata yang dipilih sehingga setiap pemilihan kata pada palet memang terlihat selaras. Ini tentu juga 
dipengaruhi oleh ekspresi rasa dari pengarang dalam menyusun teks geguritan Candrabherawa ini.

\section{Pupuh Durma}

Pupuh durma dalam teks pupuh ketujuh dalam geguritan Candrabherawa berjumlah 47 pada. Kemunculan pupuh durma kembali dalam teks geguritan ini terdapat pada halaman 38-49. Sesuai dengan kesan pengungkapan untuk mengisahkan kekacauan yang terjadi. Tidak dapat dipungkiri bahwa pupuh durma pada lanjutan teks geguritan ini digunakan untuk menceritakan alur peperangan yang terjadi antara kerajaan Dewantara dengan Hastinapura.

Alur peperangan yang menimbulkan kekecauan ini dapat terlihat pada kutipan teks geguritan berikut :

"Raris krodha sang Nakula Sahadèwa sarčng kalih ngaměsěhin, Śri Candrabhairawa, cinacah kakčmbulan,kèwala tan manmiyati, salwir sañjata, sami rusak palangkětik (geguritan Candrabherawa, pupuh durma, Pada : 2)”. Terjemahan bebasnya : lalu marahlah sang Nakula Sahadewa berdua bergantian, Sri Candrabhairawa, diserang bertubi-tubi, namun tidak berpengaruh, semua senjata, semua rusak terpental.

"Sang Nakula nuwěk antuk candrahasa, nānghing tan siddha natonin, Śri Candrabhairawa, těguhè kalintang-lintang, waluya manuwěk běsi, bělig tur luwat, kalěson sira sang kalih (geguritan Candrabherawa, pupuh durma, Pada :3)"

Terjemahan bebasnya : sang Nakula menusuk dengan Candrahasa, namun tidak bisa melukai, Sri Candrabhairawa, teguhnya sangat hebat, bagaikan menusuk besi, licin dan keras, menyerah mereka berdua.

"Mangandika Ida Sang Candrabhairawa, ih kita ripu kalih, yan kwa malěsakna, pějah kita tan pasara, kèměngan sira malaywa pwa sira, majara ri Sang Kiriti. Sang kalih (geguritan Candrabherawa, pupuh durma, pada : 4)" Terjemahan bebasnya : berkatalah ida sang Candrabhairawa, wahai kaliah musuhku berdua, kalau kalian terus melawan, gugur kalian berdua dengan sengsara, terbelalak mereka berdua, sang Kiriti, Mereka berdua.

Kutipan teks geguritan Candrabherawa diatas secara langsung menceritakan bagaimana keadaan perang dimana perlawanan yang dilakukan oleh Nakula dan Sahadewa yang terlihat marah sehingga menyerang dengan membabi buta sang raja Candra bhairawa, namun tidak ada yang mampu melukai candrabhairawa. Hal ini memperlihatkan terjadinya kekacauan yang terjadi pada peperangan tersebut, apalagi tidak mampunya Nakula Sahadewa dalam mengalahkan Candrabhairawa dalam perang tersebut. Ini merupakan sepenggal kutipan dari bagaimana terjadinya kekacauan yang disebabkan oleh perang tersebut dalam alur cerita teks geguritan Candrabherawa dalam penggunaan pupuh durma tersebut. 
Dari hasil analisa berdasarkan padalingsa dalam pupuh durma tersebut dapat disimpulkan yaitu terdapat beberapa perbedaan jumlah guru gatra pada beberapa palet dalam pada pupuh durma yang terdapat dalam teks geguritan Candrabherawa ini yang terkesan berbeda dengan pakem pupuh durma yang ada. perbedaan ini muncul cukup sering dari 47 pada yang ada, salah satunya yaitu pada 1 dan pada 2 pada palet I, III. Perbedaan ini muncul yaitu Pada palet I untuk pada 1 berjumlah 11 dan palet III berjumlah 6 sedangkan pada 2 palet I berjumlah 12 dan palet III berjumlah 7 dengan suara "a" tetap. Mengulang kembali bahwa perbedaan ini muncul karena pengarang tetap ingin mempertahankan alur ceirta sehingga jumlah guru gatra dengan pemilihan kata pada palet sedikit berbeda. Namun perbedaan ini rasanya tidak terlalu merubah makna sehingga tetap harmonis dan selaras setiap pemilihan kata yang digunakan.

\section{Pupuh smarandana}

Tjok. Istri Agung Mulyawati R. (2017) menyebutkan bahwa smarandana berasal dari kata "asmara" dan "dana". Dimana "dana" merupakan kependekan dari kata dahana yang berarti Api. Jadi smarandana dapat berarti "api asmara" (2017:6). Pupuh smarandana dapat dartikan sebagai pupuh yang cenderung pembahasaannya untuk mengungkapkan isi asmara atau kerinduan. Pupuh smarandana dalam teks pupuh kedelapan dalam geguritan Candrabherawa berjumlah 28 pada. Penggunaan pupuh smarandana sebagai pengungkapan kerinduan dalam hal ini pada teks geguritan Candrabherawa terdapat pada kutipan teks sebagai berikut :

"Sang Dharmmasuta ling nyaris, Dèwa Dyah Ratna Saśangka, mwah Dèwa Sang Candranatha, tan sandang malih pañjangang, apan karmmanè manitah, nè malu suba manandur, krana ada jani pupwang (geguritan candrabherawa, pupuh smarandana, pada : 24)"

Terjemahan bebasnya : Sang Dharmasuta lalu berkata, Dewa Dyah Ratna Sasangka, dan Dewa Sang Candranatha, tidak perlu lagi diperpanjang, karena karma bertitah, yang dulu ditanam, karena sekarang ada yang dipanen.

"Jalan ne jani kawitin, bibitè mčlah sambëhang, sinah mělah hëntikannè,dwaning suba sinah pisan, bwina tong siddha lempasang. apa tandur kèto pupu, manut ucaping agama. (geguritan candrabherawa, pupuh smarandana, pada : 25)"

Terjemahan bebasnya : mari kita mulai kembali, bibit yang baik yang kita tanam, sehingga bagus tumbuhnya, karena sudah seperti ini, karena sudah tidak bisa dihindarkan lagi, apa yang ditanam itu yang dipanen, benar seperti yang diajarkan oleh agama.

"Minab suba titah Widhi, pacepuk Kārmma Sanyaşa, lawan Yoga Sanyaşane, rèh mula kapatut tunggal, tan siddha pacang sampūrnna, yan tan sami padha 
wruh, kadi Siwa lawan Buddha (geguritan candrabherawa, pupuh smarandana, pada : 26)"

Terjemahan bebasnya : mungkin sudah titah dari Widhi, bertemu Karma Sanyasa dengan Yoga Sanyasa, karena satu yang tunggal, tidak mungkin bisa sempurna, kalau tidak semua tahu, bagaikan Siwa dan Buddha.

Apa yang sudah dijelaskan dalam teks geguritan Candrabherawa berikut kerinduan yang dimaksud adalah adanya kata-kata halus yang diucapkan sebagai bentuk perdamaian antara sang Prabu Yudistira dengan Sang Prabu Candrabherawa. Kerinduan dalam artian bukan percintaan melainkan perdamaian dimana terjadi antiklimaks cerita peperangan tersebut.

Padalingsa pupuh smarandana terdapat perbedaan pada beberapa palet dan pada. Pada yang berbeda cukup signifikan ditemukan salah satunya pada pada 1 dan ke 2 palet I dan VII. Perbedaan pada jumlah guru gatra yaitu pada 1 palet I berjumlah 8 dan palet VII berjumlah 8 , sedangkan pada 2 palet I berjumlah 9 dan palet VII berjumlah 9. Perbedaan suara juga terdapat pada beberapa pada dan palet dalam pupuh sinom ini, pada tersebut terdapat pada 4 dimana pada palet $\mathrm{V}$, mayoritas menggunakan suara "a" sedangkan pada 4 palet VII menggunakan suara "e". dapat disimpulkan seperti pada penjelasanpenjelasan sebelumnya bahwa perbedaan Padalingsa pada masing-masing pada diperkirakan pengarang tetap ingin mempertahankan alur cerita sehingga pemilihan kata pada masing-masing palet terkesan keluar dari pakem sehingga terjadi perbedaan jumlah guru gatra dan perbedaan pemilihan suara. Sehingga secara teks tidak terlalu mencolok dan tidak mengubah kesan estetika dalam menggendingkannya.

\section{Pupuh durma}

Pupuh durma dalam teks pupuh kesembilan dalam geguritan Candrabherawa berjumlah 10 pada. Pupuh durma dalam hal ini merupakan pupuh terakhir dan dapat dikatakan sebagai pupuh penutup. Walaupun pada awal-awal dijelaskan bahwa penggunaan pupuh durma lebih mencerminkan kepada pengungkapan suasana buruk namun pada teks geguritan Candrabherawa ini lebih kepada penutup sebuah cerita, tidak ditemukan sama sekali gending yang terkesan buruk. Lebih kepada penutup teks geguritan. Penutup ini tercermin pada kutipan berikut :

"Geguritan pawangun I Këtut Ruma, ring Pandhè Kawan Jaśri, Klurahan Subagan, Amlapura nāgara, panguntat ONG Santi Santi Santi, dumadak swècchä, Ida Hyang Prama Kawi (geguritan candrabherawa, pupuh smarandana, pada : 10)"

Terjemahan bebasnya : geguritan yang disusun oleh I Ketut Ruma dari Pande Kawan jasri, Kelurahan Subagan, Kabupaten Kota Amlapura, ucapan terakhir Ong Santi santi santi, semoga menganugerahi, Ida Hyang Prama Kawi. 
Pupuh durma dalam teks geguritan Candrabherawa sebagai pupuh terakhir dari analisa Padalingsa dapat disimpulkan beberapa hal yaitu terdapat perbedaan jumlah guru gatra pada beberapa pada dan palet. Ini terlihat pada jumlah pada 1 dan pada 2 pada palet I, VI dan VII. Perbedaan ini terlihat pada 1 palet I berjumlah 11, palet VI berjumlah 5 dan palet VII berjumlah 8 , sedangkan pada 2 palet I berjumlah 12, palet VI berjumlah 6 dan palet VII berjumlah 7 . Sebagaimana pada penjelasan sebelumnya bahwa perbedaan padalingsa ini lebih kepada pemertahanan pengarang dalam menggunakan kata sehingga walaupun terjadi penyimpangan dan perbedaan jumlah guru gatra namun tidak merubah terlalu besar kesan dari yang digambarkan dalam teks geguritan dan tidak merubah ekspresi estetika dari geguritan Candrabherawa.

\section{Kesimpulan}

Secara garis besar dapat disimpulkan bahwa teks geguritan Candrabherawa merupakan sebuah karya sastra yang sangat luar biasa. Bagaimana tidak dari struktur teks sudah memiliki berbagai komponen yang sangat Kompleks mulai dari tema sampai dengan penggunaan pupuh yang sangat baik. Setiap pupuh yang digunakan sangat tepat menggambarkan setiap plot dan alur dalam cerita yang digambarkan sehingga kesan-kesan dalam setiap cerita memang tergambarkan secara jelas dengan penggunaan pupuh-pupiuh tersebut. Lebih dalam bahwa teks geguritan Candrabherawa memiliki struktur teks yang cukup unik dan didalamnya terkandung nilai-nilai pendidikan serta nilai fislafat keagamaan yang sangat dalam, ajaran-ajaran agama Hindu yang terkandung didalamnya sangat suci. Pengkajian teks geguritan ini tidak hanya sekedar pengakajian struktur semata namun dalam prosesnya ternyata ditemukan berbagai hal yang menarik khusunya terkandungnya berbagai ajaran luhur suci Hindu.

\section{Daftar pustaka}

Amidong, H. H. (2016). Penokohan Dalam Karya Fiksi. Fakultas Sastra, Universitas Musilm Indonesia.

Anak Agung Istri Dwi Wulandari, I Wayan Mandra, G. D. D. S. (2018). Nilai-Nilai Pendidikan Agama Hindu Yang Terkandung Dalam Geguritan Lubdaka. Jurnal Penelitian Agama Hindu, 2(1), 1-5. Https://Doi.Org/10.1017/Cbo9781107415324.004

Bagus, I., Nandana, D., Istri, T., Mulyawati, A., \& Putu, L. (2017). Geguritan Aji Rama Rena Analisis Struktur Dan Makna. Humanis, Journal Of Arts And Humanities, 20, 304-309.

Budiasa, I. N. (2019). Nilai-Nilai Pendidikan Agama Hindu Dalam Teks Gaguritan Tam Tam. Jurnal Penelitian Agama Hindu, 3(2), 304-306.

Dhanu Priyo Prabowo, V. Risti Ratnawati, Suyami, Mumfangati, T. (2002). 
Geguritan Tradisional Dalam Sastrajawa. Pusat Bahasa Departemen Pendidikan Nasional.

Dyah Nur Lailyana. (2017). Analisis Gaya Bahasa Pada Geguritan Dalam Majalah Djaka Lodang Edisi 3 Oktober 2015 - 2 April 2016. Aditya, (02), 1-10.

Gde Bagus Made Surya Pradnyana, I Wayan Augita, I. G. N. M. (2018). Geguritan Begawan Dharma Swami (Kajian Nilai Pendidikan Agama Hindu). Jurnal Penelitian Agama Hindu, 2(2), 552-558. Https://Doi.Org/10.1017/Cbo9781107415324.004

Gunada, I. W. A. (2020). Ajaran Agama Hindu Dalam Geguritan Candrabherawa Sebagai Penguatan Pendidikan Karakter. Kamaya: Jurnal Ilmu Agama, $3(2)$, 102-119.

Https://Doi.Org/Https://Doi.Org/10.37329/Kamaya.V3i2.434

I Made Budiasa, I. M. S., \& Sukrawati, Cokorda Lstri Negari, N. P. E. (1997). Konsep Budaya Bali-Dalam Geguritan Sucita Subudhi. Repositori.Kemdikbud.Go.Id. Https://Doi.Org/10.1017/Cbo9781107415324.004

Sri Ulina Beru Ginting. (2017). Struktur Alur Dan Bentuk Konflik Yang Membangun Novel Saman Karya Ayu Utami. Jurnal Pena Indonesia, 3(2), 130-146.

Sura, I. M., Loka, W., Sudarsana, I. K., \& Artayasa, I. W. (2019). Nilai Pendidikan Karakter Dalam Geguritan Wirotama. Jurnal Penelitian Agama Hindu, (Sinta 5), 75-79.

Tjok. Istri Agung Mulyawati R. (2017). Kajian Bentuk Sastra Paletan Tembang Geguritan I Ceker Cipak. Retrieved From Https://Simdos.Unud.Ac.Id/Uploads/File_Penelitian_1_Dir/3fb4642685c ode40cdaa1924ffid77a4.Pdf

Wijaya, N. (2014). Apakah Agama Hindu Bali Modern Lahir Dari Tantangan Pancasila Dan Islam. Jurnal Kajian Bali (Journal Of Bali Studies), 4(1), 1415 . 